\title{
Ethnic Differences in Disability Risk between Dutch and Turkish Scaffolders
}

\author{
L.A.M. Elders ${ }^{1,2}$, A. BURDORF ${ }^{1}$ and F.G. ÖRY ${ }^{3}$
}

${ }^{1}$ Department of Public Health, Erasmus MC, University Medical Center Rotterdam, ${ }^{2}$ Occupational Health Service Maetis, Capelle a/d IJssel and ${ }^{3}$ TNO Prevention and Health, Leiden and Foundation Pacemaker in Global Health, The Netherlands

\begin{abstract}
Ethnic Differences in Disability Risk between Dutch and Turkish Scaffolders: L.A.M. ELDERS, et al. Department of Public Health, Erasmus MC, University Medical Center Rotterdam, The Netherlands-The number of native Dutch and Turkish workers receiving a permanent disability pension in the Netherlands is still rising. To assess ethnic differences in disability risk between Dutch and Turkish scaffolders, a retrospective study was conducted within a large scaffolding company. Medical files for the period 19812000 were used to gather information on ethnicity, age at entering service, age at becoming disabled, years of employment, the year to receive a disability pension, the disability diagnosis, and the percentage rating of the disability pension. In the past $20 \mathrm{yr}, 131$ Turkish and 125 Dutch scaffolders have become disabled. Musculoskeletal disorders were the primary reason for the diagnosis. No differences in diagnoses were observed, except for a small difference in cardiovascular disease. Turkish scaffolders started their work at an older age, received the disability pension at an older age, and had a longer duration of employment. Turkish scaffolders faced disability 2.48 (95\% confidence interval 1.94-3.18) times more often than their Dutch colleagues, adjusted for age. Explanations for the differences in disability risk between Dutch and Turkish scaffolders are sought in the older age at start of employment, lower mobility in the labour market, and less access to medical and social care. In future, employers, general practitioners, occupational health physicians and social security workers, as stakeholders in reintegration, should sufficiently attune their activities concerning care and cure for Turkish construction workers on long-term sick
\end{abstract}

Received Nov 4, 2003; Accepted July 22, 2004

Correspondence to: L.A.M. Elders, Erasmus MC, University Medical Center Rotterdam, Department of Public Health, PO box 1738, 3000 DR Rotterdam, The Netherlands

(e-mail: l.elders@erasmusmc.nlorelders77@zonnet.nl) leave or during reintegration into other work. (J Occup Health 2004; 46: 391-397)

Key words: Disability, Ethnicity, Risk factors, Reintegration, Retrospective study, Scaffolders

In the Netherlands the social security system is based on legal rights granting workers on sick-leave payment of salary for a maximum period of one year. In 1998 the sickness absence rate in the Netherlands was 5.0\%. From 1999 until 2002 this rate increased to $5.4 \%$. In a working population of almost 8.5 million people this means that more than 450,000 workers are on sick leave every day. The statistics failed to show a breakdown of ethnic differences in sickness absence ${ }^{1)}$. If there is no return to work within one year, workers on sick leave can file for a disability pension, which grants compensation for the loss of income to a maximum of $70 \%$. Despite good intentions, legislation on work related disability has thus created great opportunities for workers to compensate for their loss of income, causing an unprecedented rise in claims.

In 1998 , disability benefits were being paid to $13.2 \%$ of the labour force, a figure that varied in the rest of Western Europe between $3.1 \%$ in Spain and $11.9 \%$ in Sweden. In 2002 this figure increased to $14.7 \%$ of the labour force 14-65 yr old, meaning that almost 1 million workers in the Netherlands were receiving disability benefits ${ }^{1,2)}$.

According to the State Secretary, the increase was chiefly due to the expanding economy in last decade of the last century ${ }^{3)}$. In fact, shortage of labour opens up opportunities for employees from relatively deprived socio-economic groups: they are poorly educated, do the heaviest work, and tend to belong to ethnic minority groups. But this explanation fails to take into account that members of ethnic minority groups are strongly overrepresented in occupations with a high risk of workrelated disorders. According to the Netherlands Statistics 
in 1999 considerable differences in disability rates existed between Turkish and Dutch men: $40 \%$ of the Turkish men aged 40-64 are disabled compared with $17 \%$ of native Dutch men in the same age group ${ }^{4,5)}$. Some 11,000 Turkish workers were paid disability pensions compared with 359,000 Dutch. Nevertheless, these figures only provide information about incapacity in combination with age and ethnicity, but no information is provided about occupation and disability diagnosis differentiated according to ethnic background.

To put these figures into perspective, it should be remembered that in the Netherlands more than $5 \%$ of the Dutch population is not of native origin. The Turkish population of more than 230,000 inhabitants are the largest ethnic minority group representing almost $25 \%$ of the total ethnic population ${ }^{6}$. This is also applicable to the scaffolding industry. With approximately 3,000 people working in this branch of industry, it is one of the smallest industries compared with the construction industry at large, employing over 300,000 workers. Only a few scaffolding companies employ more than 100 scaffolders and most companies employ less than 50 workers $^{7)}$. A sector well known for its high disability rate is the construction industry. In 1998, 32 workers received a disability benefit out of every one hundred construction workers. Unfortunately, no breakdown according to ethnic background was available. Of all workers in the construction industry the scaffolding industry had the highest 4-yr disability rate $(7.3 \%)$ between 1995 and 1998, whereas the average Dutch labour force had a disability rate of only $1-2 \%$ in the same period ${ }^{7)}$.

In this article the differences in disability pensions between Turkish and Dutch workers are presented. The question is what is causing these differences and why do Turkish scaffolders have a higher disability risk than their Dutch colleagues?

\section{Methods}

The study population comprised all 256 disabled Dutch and Turkish men employed as scaffolders at a large scaffolding company in the Netherlands between 1981 and 2000. To qualify for the study, Turkish workers had to be born in Turkey or have at least one parent who was born in Turkey. From the native Dutch group both parents had to be born in the Netherlands. All scaffolders were subject to the same physical workload. The principal tasks of scaffolders are carrying poles and boards and erecting and taking down large scaffolds. During these tasks manual handling of materials is one of the most dominant activities due to manual lifting, lowering, and carrying of heavy materials with in total between 5,000 and 15,000 kilos on a daily basis ${ }^{8)}$.

Every company in the Netherlands is obliged by law to contract an independent occupational health service for support and assistance concerning occupational health issues including a policy for reducing sickness absence and disability. The scaffolding company in this study choose to have an occupational health service on their own premises, managed by the human resource manager of the scaffolding company.

Medical files from the occupational health service were available to gather information about ethnicity, age at entering service, age at becoming disabled, years of employment, year to receive a disability benefit, disability diagnosis, and the percentage rating of the disability pension. The rating of the disability benefit after one year of sick leave was estimated by an independent social security officer employed by the government. A disability benefit was only granted if the loss of income, due to the functional limitations resulting from the disability diagnosis, exceeded $15 \%$ or more. Therefore, depending on the loss of income there are 8 disability pension categories: $<15 \%, 15-25 \%, 25-35 \%, 35-45 \%, 45-55 \%$, $55-65 \%, 65-80 \%$ and $80-100 \%$. All medical files contained the official correspondence with the social security officer including the disability pension granted.

Medical files of all subjects were available, but in some files individual information such as the period they had worked in a given year and the exact age they had started working in the scaffolding company were missing. Nevertheless, information was available on the total number of workers at the beginning and at the end of each year, either Dutch or Turkish. Therefore, the analysis focused on aggregated data, based on the size of the workforce during the period 1981-2000.

At no time did the workforce expand or shrink more than $10 \%$ within the span of a year. It was then decided to make the number of person years equivalent to the mean number of employees in that year. This method of calculation will lead to a slight overestimate of the actual number of person-years, as the term of employment was less than a year for a number of the scaffolders. The annual disability risk was calculated as the number of persons becoming disabled in each group divided by the number of person-years in each group in that same year. The availability of all information on the individual level during the last four years of this study, made it possible to form a dynamic cohort. The data were used to estimate the disability risk in relation to ethnicity, age, and length of employment.

Differences between distributions of continuous variables were examined with the Student's $t$ test. Poisson regression was used to calculate the disability risk per 100 person years (rate) during the period 1981-2000. Differences in disability risk per 100 person years are expressed as the incidence rate ratio (RR), adjusted for age at the time of entry into the government disability pension scheme.

A survival-analysis was performed for the period 1997- 


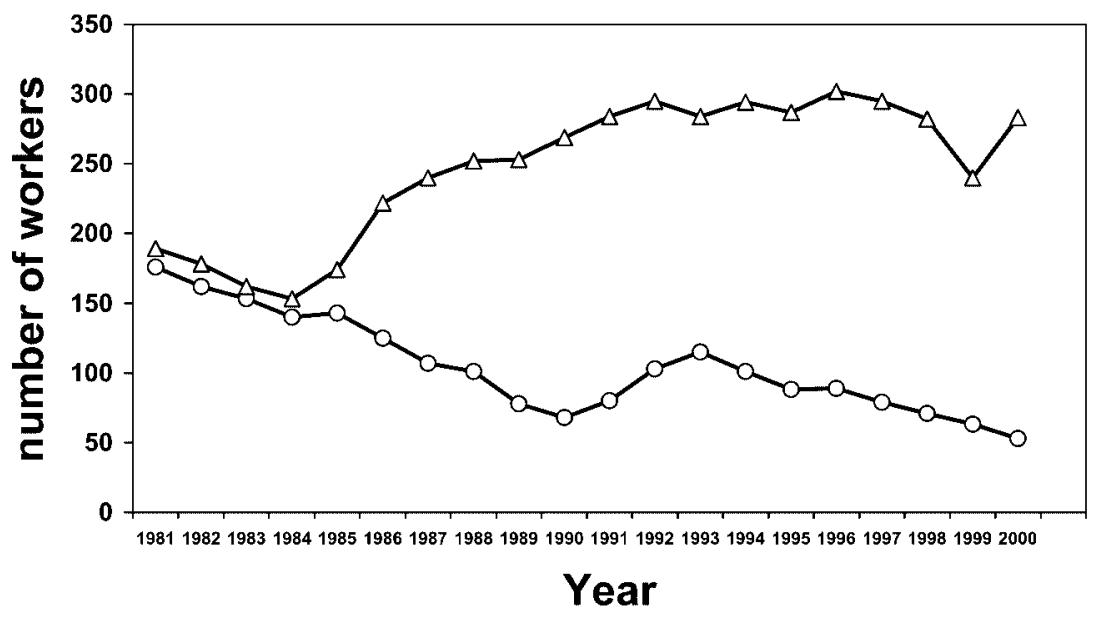

\section{$\multimap-$ Turkish $\rightarrow-$ Dutch}

Fig. 1. Distribution of Dutch and Turkish scaffolders in the scaffolding company between 1981 and 2000

Table 1. Personal data on disabled workers of Dutch and Turkish origin and the disability diagnosis

\begin{tabular}{|c|c|c|}
\hline Personal data and disability diagnosis & $\begin{array}{l}\text { Dutch scaffolders } \\
\qquad(\mathrm{n}=125)\end{array}$ & $\begin{array}{c}\text { Turkish scaffolders } \\
\qquad(\mathrm{n}=131)\end{array}$ \\
\hline \multicolumn{3}{|l|}{ Personal data } \\
\hline \multicolumn{3}{|l|}{ Age on entering employment } \\
\hline $\begin{array}{l}\text { Age on entering the government } \\
\text { disability pension scheme* }\end{array}$ & $38.6 \pm 10.9$ & $43.7 \pm 9.8$ \\
\hline Years of employment* & $9.6 \pm 7.5$ & $12.5 \pm 6.2$ \\
\hline \multicolumn{3}{|l|}{ Disability diagnosis } \\
\hline Back disorders & $21(17 \%)$ & $32(24 \%)$ \\
\hline Other musculoskeletal disorders & $26(21 \%)$ & $18(14 \%)$ \\
\hline Accidents & $16(13 \%)$ & $15(12 \%)$ \\
\hline Psychiatric disease & $10 \quad(8 \%)$ & $11 \quad(8 \%)$ \\
\hline Cardiovascular disease & $5 \quad(4 \%)$ & $11 \quad(8 \%)$ \\
\hline Other disorders & $18(14 \%)$ & $19(15 \%)$ \\
\hline Unknown & $29(23 \%)$ & $25(19 \%)$ \\
\hline
\end{tabular}

${ }^{*} p<0.05, t$-test

2000 in which the time of employment until a worker became disabled was used as an independent variable and ethnicity, age at entering service, and age at becoming disabled were used as dependent variables. Censoring was defined as leaving the company or receiving a disability pension. The differences between disability risks were calculated as Relative Risks.

\section{Results}

Figure 1 presents the distribution of Dutch and Turkish scaffolders between 1981 and 2000 in the scaffolding company. Information about the workforce during the period 1980-1985 showed that $45 \%$ of the scaffolders were of Turkish origin. After 1985, the percentage dropped, reaching only $16 \%(n=53)$ out of a total of 336 scaffolders in 2000.

Table 1 shows the personal information and disability diagnoses of 131 Turkish (T) and 125 Dutch (D) scaffolders between 1981 and 2000. Turkish workers started working at an older age, were employed longer, 
Table 2. Age and number of years of employment on entry into the government disability pension scheme, according to disability diagnosis

\begin{tabular}{lcc}
\hline Disability diagnosis & Age on entering the disability scheme* & $\begin{array}{c}\text { Years of employment on } \\
\text { entering disability scheme* }\end{array}$ \\
\hline Back disorders & $40.0 \pm 10.3$ & $11.2 \pm 6.6$ \\
Other musculoskeletal disorders & $42.7 \pm 9.9$ & $11.4 \pm 6.4$ \\
Accidents & $39.4 \pm 11.2$ & $9.4 \pm 6.9$ \\
Psychiatric diseases & $34.0 \pm 9.5$ & $7.6 \pm 7.1$ \\
Cardiovascular diseases & $50.9 \pm 6.1$ & $16.6 \pm 6.4$ \\
Other disorders & $44.7 \pm 10.2$ & $11.8 \pm 7.2$ \\
\hline
\end{tabular}

*average and standard deviation

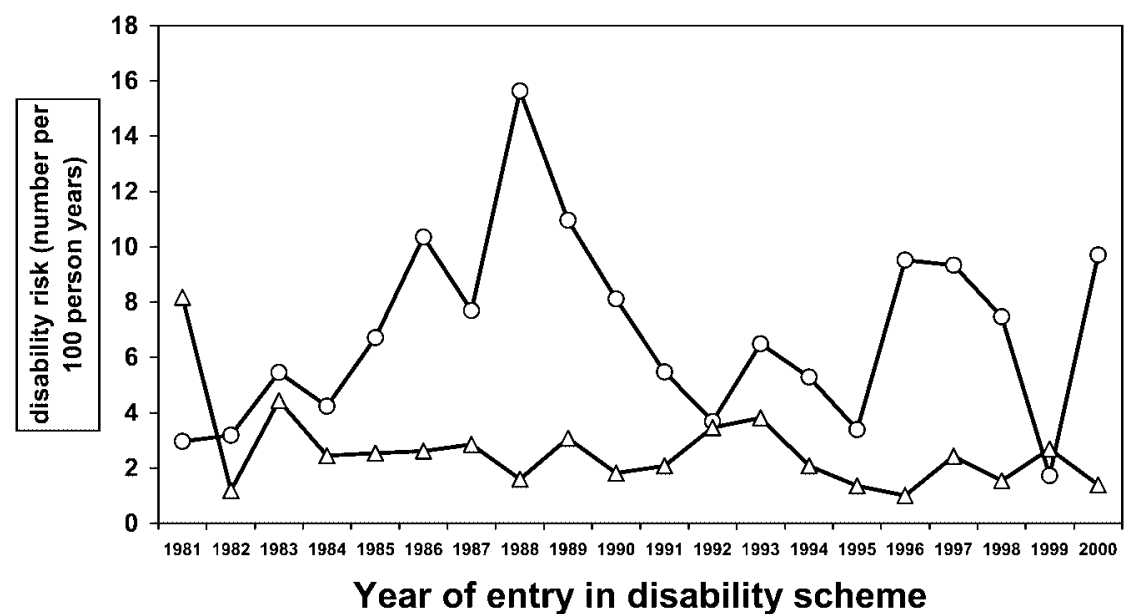

\section{$\rightarrow$ Turkish $\rightarrow-$ Dutch}

Fig. 2. Annual disability risk among Dutch and Turkish scaffolders at a scaffolding company over the period 1981-2000.

and became disabled at an older age. In 54 cases, evenly distributed over the two groups, a disability diagnosis was lacking. Of the 202 remaining cases, $48 \%(n=97)$ suffered from musculoskeletal disorders, of which $26 \%$ were back-related disorders. Except for neck problems (D:5, T:1), all other musculoskeletal problems were distributed relatively evenly. Accidents, at $15 \%$, ranked second as the reason for receiving disability benefits, and psychiatric problems, at $10 \%$, third. Accidents $(n=31)$ mainly took place at work $(n=19)$ and in traffic $(n=7)$. A significant difference emerged for cardiovascular disorders (D:5; T:11; $p=0.03$ ). Although not significant, differences were also found for pulmonary diseases (D:3; $\mathrm{T}: 8$ ), whereas malignancies were solely observed in the Dutch group (D:4). It was established that working conditions played no role in the worker's incapacitation in 52 of 202 cases (26\%). Of 55 files containing information about the disability rating, $45 \%$ were rated at less than $35 \%, 31 \%$ were between $35 \%$ and $55 \%$, and $24 \%$ had a disability rating of $80-100 \%$.

Table 2 shows the age and years of employment per diagnosis at entry into the disability pension scheme. The distribution of diagnoses remained unchanged over a 20yr period. Scaffolders with psychiatric disorders were significantly younger and had on average worked fewer years. Cardiovascular disease occurred at an older age and after a longer period of employment. In the case of an accident, the age at entering employment was significantly higher for the Turkish (age 45.1) than for the Dutch group (age 35.0). As hardly any differences were found in disability diagnoses between the two groups, it was decided to present this table without differentiating according to ethnicity.

Figure 2 shows the annual risk of becoming disabled expressed as the number of disabled workers per 100 person-years. This risk, for the entire group of scaffolders 


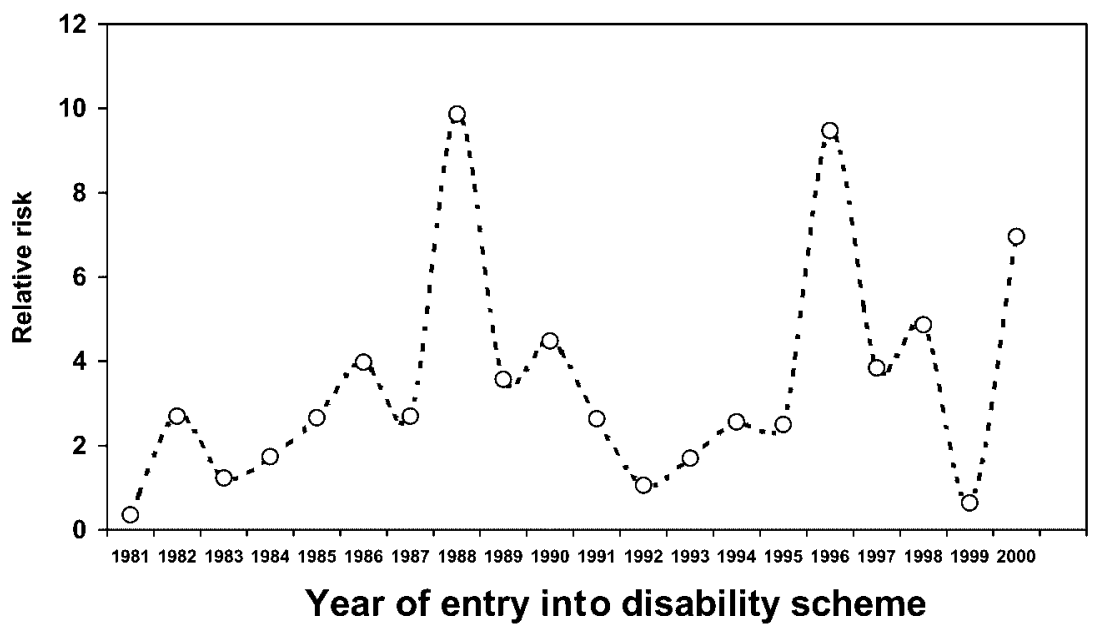

Fig. 3. Relative risk of disability among Dutch and Turkish scaffolders at a scaffolding company over the period 1981-2000.

in the $20 \mathrm{yr}$-period was $3.5 \%$ per 100 person-yr and varied annually from $1.8 \%$ to $5.4 \%$. The mean disability risk was significantly higher for Turkish than for Dutch scaffolders: $6.4 \%$ and $2.5 \%$ respectively. The risk ratio of Turkish compared with Dutch scaffolders becoming disabled was 2.57 (95\% confidence interval 2.01-3.29). In 18 out of $20 \mathrm{yr}$ the disability risk was higher for the Turkish group (Fig. 3). Poisson regression analysis showed no continuous trend in disability risk over the 20-yr period for either group. A marked dividing line in disability risk was seen before 1994, the year in which new legislation on sickness absence was enacted. Just one year before that, in August 1993, the criteria for eligability for disability pensions had already been changed.

Prior to 1994 , the risk of becoming disabled as a scaffolder was $4 \%$; this subsequently dropped to $2.7 \%$. The ratio of this cut-off point was 1.50 (95\% confidence interval 1.14-1.98). After adjustment for ethnicity this ratio declined slightly to 1.31 (95\% confidence interval 0.99-1.73), which was caused by the smaller decrease among Turkish than among Dutch scaffolders over the period 1981-2000. The disability risk for the Turkish workers compared with the Dutch group was 2.48 (95\% confidence interval 1.94-3.18), adjusted for age. The dynamic cohort of scaffolders during the period 19972000 showed an average disability entry rate of almost $3 \%$ per 100 person-years. The relative risk (RR) was 3.31 (95\% confidence interval 1.54-7.14) for Turkish scaffolders compared with their Dutch colleagues. After adjustment for age at cohort entry $(R R=1.08,95 \%$ confidence interval 1.04-1.12) the RR for ethnicity dropped $26 \%$ to 2.45 (95\% confidence interval $1.12-$
5.35). Years of employment were not significant, after adjusting for age at cohort entry.

Regarding reintegration of disabled Turkish and Dutch scaffolders over the past $7 \mathrm{yr}, 12$ Dutch scaffolders resumed work at the scaffolding company, compared with not a single Turkish worker.

\section{Discussion}

Scaffolders perform a very heavy job and are exposed to high physical workloads characterised by awkward back postures, in which the back is often bent and twisted, with high strenuous arm movements when working with one or two arms above shoulder level, and manual material handling of heavy loads every day. Psychosocial risk factors in this occupation are of lesser importance ${ }^{9)}$.

The population of scaffolders in this study has to be considered a representative sample of all scaffolders in the Netherlands. They were working in the largest scaffolding company in the Netherlands, representing $12 \%$ of the total number of scaffolders in the Netherlands. In fact, the disability characteristics of this scaffolding company directly reflected the disability rate of the scaffolders in the rest of the Netherlands.

Although the occupational health conditions were exactly the same for Dutch and Turkish scaffolders, the data from this study show that Turkish scaffolders have a higher risk of becoming disabled than their Dutch colleagues. Netherlands Statistics calculated that the risk of becoming disabled was 1.51 for Dutch workers, a risk that was considerably higher for Turkish scaffolders ${ }^{4}$. This invokes questions about the role played by ethnicity. The Turkish workers commenced work and became disabled at a significantly older age (2 and $5 \mathrm{yr}$ 
respectively) and had usually been employed for a longer period (3 yr). Unfortunately, some data were missing during the period 1981-1996, but a complete data set from 1997 to 2000 revealed that the relative risk for ethnicity calculated in the survival analysis and adjusted for age decreased from 3.31 to 2.45 . If the distribution of age during this period is considered to represent the age distribution during the whole period from 1981 to 2000 , the adjustment for age accounted for a $26 \%$ decrease in disability risk for Turkish and Dutch scaffolders. Therefore, it is plausible to suppose that an important part of the perceived differences in disability risk is not explained by age or years of employment, but reflects ethnicity.

Dutch and Turkish scaffolders who applied for a job as a scaffolder were all invited for a pre-employment medical selection before they were offered a contract. Health selection criteria were the same for both groups. Candidates suffering from severe musculoskeletal disorders, neurological, psychiatric, or pulmonary disease and aged 45 yr or more were rejected for a job as a scaffolder. Therefore, pre-employment medical selection does not satisfactorily explain the differences in disability risk.

In many cases disabled Turkish scaffolders were firstgeneration Turks from the eastern part of Turkey. On coming to the Netherlands they belonged to the relatively healthier part of the population. After all, based on the "healthy migrant effect", only a relatively healthy subgroup will emigrate to seek work abroad ${ }^{10)}$. But from the moment Turkish workers went to work as scaffolders in the Netherlands, there was no longer any question of selection on the basis of ethnicity. In this context it would be interesting to know for how many years the Turkish workers had already done heavy physical work in their home-country before emigrating to the Netherlands.

Although in 1991 major differences were observed between the Turkish and the Dutch communities in the general population concerning chronic ailments, the literature abroad shows that patterns of illness among ethnic minority groups gradually start to converge with those of the host country. This is perhaps part of the explanation why the diagnoses on the basis of which both Turkish and Dutch workers received disability benefits showed very few differences ${ }^{11,12)}$. Another explanation could be the similarity in working conditions for the two groups.

According to Table 2 psychiatric complaints mainly occur at a relatively young age. It is a well-known fact that after only a few years of employment many health problems in persons from ethnic minority groups tend to be psychosomatic ${ }^{13}$. Despite this, the distribution of the disability diagnosis of 'psychiatric complaints' over time shows no difference between Turkish and Dutch scaffolders. Striking is the fact that accidents hold second place. Turkish scaffolders suffering an accident were older when entering employment. It seems that sufficient attention must be given to provide this group with comprehensible safety instructions. After all, older Turkish workers are less fluent in Dutch, and accidents are the result of inadequate observation of the safety precautions.

Cardiovascular problems are a different matter altogether. Turkish scaffolders are older and have been employed longer than their Dutch colleagues at the time they become disabled because of cardiovascular disease. In the general community heart disease occurs at a later age and therefore it will have an impact on the age at which workers become incapacitated, but the difference between Dutch and Turkish scaffolders in cardiovascular disability is somewhat unexpected because statistics from the general community showed no difference between the Dutch and the Turkish groups with respect to the prevalence of heart problems ${ }^{10)}$. Therefore, age and length of employment seemed to be important factors for Turks in developing cardiovascular disease.

Health complaints and disorders tend to increase with age. Based on this phenomenon scaffolders preferably exposed to high physical load during work are more prone to suffer from musculoskeletal disorders. Nevertheless, if age was a predominant factor in an increased disability risk, the difference between Dutch and Turkish scaffolders could only be explained if the distribution of disability diagnosis differed significantly between the both groups. Cardiovascular disease was the only diagnosis to show any difference between the two groups. Therefore, ageing seems not to be the major factor of importance to explain the increased disability risk in Turkish scaffolders, still leaving ethnicity as one of the discriminating factors to be assessed.

If health problems of any kind persist for too long, reintegration recedes wholly into the background and disability becomes a reality. Studies have shown that of all ethnic minority groups Turks in particular report a significantly higher rate of physical complaints and longterm functional limitations. Furthermore, Turks aged 35 and over were found to use far more pharmaceuticals and make more use of the primary health care system than other ethnic minority groups. They also consult medical specialists the least ${ }^{14,15)}$. Ensuring adequate care at the right moment is a necessary requirement for recovery and reintegration.

Figure 2 shows that the risk for Dutch scaffolders ranged from $1.0 \%$ to $4.4 \%$ over $20 \mathrm{yr}$. Truly staggering is the disability risk for Turkish scaffolders, which is shown to be 2.48 times that of the Dutch group. Two peaks emerge for the Turkish scaffolders (in 1986/1988 and 1996/1997). The first peak mainly comprises the first generation of Turkish workers. The second peak is a matter of speculation, as two generations of Turkish 
employees were working at this company at the time. Therefore, the exact reason for this second peak remains unclear

The reduction in disability risk seen in 1994 corresponds with the national trend and the introduction of a law, in August 1993, which meant to reduce the possibility to file for a disability pension by changing the criteria of entry ${ }^{16)}$. The extent to which confusion and uncertainty about the social security situation by Turkish scaffolders played a role in this temporary decline in the risk is not clear ${ }^{17)}$.

There is enough evidence arguing in favour of extra attention for workers from ethnic minority backgrounds. The fact that the flexibility and employability of these employees tends to be a weak point is well known ${ }^{16)}$. There are various reasons for this: the difficult position on the labour market, their difficulty in accessing facilities to promote reintegration, language and communication difficulties, low level of education, and the older age when entering the disability scheme. Furthermore, Dutch guidelines for reintegration and rehabilitation do not take into account ethnic differences. Therefore, the question is whether reintegration should not be preceded first by integration into society. This problem may also hold true for other occupational groups across national borders.

In addition, care practitioners, employers, occupational health physicians, and social security workers, should have knowledge of the differences between workers from ethnic minority groups and native Dutch ${ }^{18)}$. After all, different ideas about care and a different perception of the capacity to work may well act as a barrier to successful reintegration $^{13,19)}$. Furthermore, these ethnic minority groups remain close as a community and have little experience with networks outside their own group. This may hamper their ability to find another job. Nevertheless, in the search for an answer, it would seem wise to pay attention to intercultural communication and to specifically targeted, tailor made solutions, in the effort to offer this highly vulnerable group in society a new opportunity in the labour market.

Acknowledgments: We wish to offer Karien Stronks of the Institute of Social Medicine, University of Amsterdam and Peter Gabeler, Staff-medical insurance officer, State Social Insurance Office, our grateful thanks for critically reading the manuscript and for their contribution to this article.

\section{References}

1) Netherlands Statistics. Social-economic trends. Statistical quarterly about the labour-market, social security and income. 2004; 1: 1-65.

2) LElders and A Burdorf: Extensive legal measures failed to reduce claims on disability. Tijdschr Gezondheidsw; $78,453-454$ (2000)

3) L Zwiggelaar: State Secretary Hoogervorst: "An expanding economy increases the number of disabled workers". Rendemens 2, 17-18 (2000)

4) Netherlands Statistics. Disability among Dutch workers and workers of ethnic minorities. Press-release 2000:PB00-262.

5) Snel E, Stavenuiter M, Duyvendak JW. Trapped. Disability in Turkish and Marrocan workers. VerweyJonker Instituut, Utrecht. April 2002.

6) Netherlands Statistics: Population trends. Statistical quarterly on demography in the Netherlands 2004; 1 : $1-65$.

7) Ploeger A. Disability in the construction industry. Amsterdam: Economical Institute for the Construction Industry (EIB) 2001.

8) M Dawson, P Kleppe, A Van der Beek, A Burdorf and L Elders: Physical and postural load and working tasks of scaffolders. Tijdschr Ergonomie 24, 134-139 (1999)

9) LAM Elders and A Burdorf: Interrelations of risk factors and low back pain in scaffolders. OEM 58, 597603 (2001)

10) Mackenbach JP. Migrants, migration and health care, In: Haveman, HB en Uniken Venema P, eds. Migrants and health care, Houten/Diegem 1996: 30-42.

11) Van der Maas P, Mackenbach JP. Health care in the Netherlands. In: Van der Maas P, Mackenbach JP, eds. Volksgezondheid en Gezondheidszorg, second edition. Maarssen: Elsevier Bunge 1999: 102-105.

12) Rijkschroeff BR. The G.T. Healthy together, experiences of migrants with the Dutch health care system. Capelle a/d IJssel: Labyrint Publication 1992: 129-150.

13) Docter HJ. The foreign worker. In: Buijs PC, Docter HJ, van Eek WH, eds. Handboek bedrijfsgezondheidszorg, Maarssen: Elsevier gezondheidszorg, 1994: C2-C4/1-9.

14) SA Reijneveld: Social-demographic variables and the use of health care in future: which role does ethnicity play. Tijdschr Soc Gezondheidsw 79, 182-183 (2001)

15) K Stronks, ACJ Ravelli and SA Reijneveld: Immigrants in the Netherlands: equal access for equal needs? J Epidemiol Community Health 55, 701-713 (2001)

16) Willems JHBM, Koten JW, en Croon NHTh. A short historical review. In:Willems JHBM, Croon NHTh, Koten JW, eds. Handboek Arbeid en Belastbaarheid. Houten: Bohn Stafleu Van Loghum, 2001; 1: 20.

17) JF Hoogervorst. Measures to reduce illness are insufficient. Sociale Zaken. June; 27, 5 (2000)

18) Meerman MGM. Broken white. About the acceptance of ethnic minorities within organisations. Thesis. University of Leiden 1999.

19) Van Poppel J, Kamphuis P, Marcelissen F, Van Wersch SFM. Ethnic minorities, social medical support and reintegration. Instituut voor Arbeidsvraagstukken. Tilburg 2002. 